\title{
Influence of secondary electro-conductive phases on sliding wear performance of zirconia based ceramic composites
}

\author{
K. Bonny ${ }^{1, a}$, P. De Baets ${ }^{1, b}$, O. Van der Biest ${ }^{2, c}$, J. Vleugels ${ }^{2, d}$, B. Lauwers ${ }^{3, e}$ \\ ${ }^{1}$ Ghent University (UGent), Dep. Mechanical Construction \& Production, IR04, Belgium \\ ${ }^{2}$ Catholic University Leuven (K.U.Leuven), Dep. Metallurgy \& Materials Engineering, MTM, Belgium \\ ${ }^{3}$ Catholic University Leuven (K.U.Leuven), Dep. Mechanical Engineering, PMA, Belgium \\ akoenraad.bonny@ugent.be, ${ }^{b}$ patrick.debaets@ugent.be, comer.vanderbiest@mtm.kuleuven.be, \\ djozef.vleugels@mtm.kuleuven.be, ‘bert.lauwers@mech.kuleuven.be
}

Keywords: $\mathrm{ZrO}_{2}$ composite, wire EDM, surface integrity, wear rate, reciprocating dry sliding

\begin{abstract}
Zirconia-based ceramic composites such as $\mathrm{ZrO}_{2}-\mathrm{WC}, \mathrm{ZrO}_{2}-\mathrm{TiCN}$ and $\mathrm{ZrO}_{2}-\mathrm{TiN}$, are suitable for wire-EDM, due to their sufficiently electro-conductive secondary phases inside. Thus, the material removal technique of EDM to shape complex geometry materials economically and with high accuracy, irrespective of mechanical properties, could be successfully employed on these ceramics. Samples of these $\mathrm{ZrO}_{2}$-based ceramics were developed in laboratory and manufactured and surface finished by wire-EDM. Reciprocative dry sliding pin-on-plate experiments revealed that the $\mathrm{ZrO}_{2}$-WC composite exhibits better tribological characteristics in comparison with the composites of $\mathrm{ZrO}_{2}-\mathrm{TiCN}$ and $\mathrm{ZrO}_{2}-\mathrm{TiN}$. Furthermore, topographies and cross-sectional views of worn surfaces were analyzed by SEM, revealing that the secondary phase inside the investigated composites governs the wear mechanism.
\end{abstract}

\section{Introduction}

Zirconia ceramics are regarded as potential candidate materials for tribological applications. While monoclinic zirconia is less desirable because of its phase instability and low thermal shock resistance, various stabilized and toughened zirconia ceramics show a high potential for various wear applications [1]. Partially stabilised zirconia (PSZ) and tetragonal zirconia polycrystalline (TZP) ceramics are being used increasingly in engineering applications as they possess a good combination of hardness, stiffness, low density, high strength and high toughness [2].

This paper focuses on $\mathrm{ZrO}_{2}$-based composites with 40 vol \% TiN, TiCN or WC addition. These electrically conductive secondary phases allow the $\mathrm{ZrO}_{2}$-based composites to be manufactured by electrical discharge machining (EDM) $[3,4]$. The tribological behavior of wire EDM'ed samples is investigated in dry friction experiments on a small-scale pin on plate tribometer. The online measured wear depths were compared to the post-mortem obtained wear volumes, from which instantaneous wear rates can be derived as function of the wear distance.

\section{Experimental}

$\mathbf{Z r O}_{2}$-based composites. The zirconia-based ceramic composites were obtained by hot pressing of yttria-stabilised $\mathrm{ZrO}_{2}$ powder mixtures with 40 vol \% of WC, TiCN or TiN. More information on the processing and characterisation of the $\mathrm{ZrO}_{2}$-based composites is given elsewhere [5-7]. The mechanical and physical properties of these ceramics, together with the results of grain size measurements of the secondary phase in the $\mathrm{ZrO}_{2}$-based composites, obtained using Imagine-Pro Plus software, are compared in Table 1. The composites should be suitable for EDM since their electrical resistivity is higher than of $10^{-6} \Omega . \mathrm{m}[3]$. 
Table 1: Physical and mechanical properties, grain size distribution of the secondary phase and surface roughness $\mathrm{R}_{\mathrm{a}}$ and $\mathrm{R}_{\mathrm{t}}$ of the $\mathrm{ZrO}_{2}$-based composites

\begin{tabular}{|c|c|c|c|c|c|c|c|c|c|c|}
\hline $\begin{array}{c}\text { Secondary } \\
\text { Phase } \\
\end{array}$ & $\begin{array}{c}\mathrm{E} \\
{[\mathrm{GPa}]}\end{array}$ & $\begin{array}{c}\mathrm{HV}_{10} \\
{\left[\mathrm{~kg} / \mathrm{mm}^{2}\right]}\end{array}$ & $\begin{array}{c}\mathrm{K}_{\mathrm{IC}} \\
{\left[\mathrm{MPa} \cdot \mathrm{m}^{1 / 2}\right]}\end{array}$ & $\begin{array}{l}\text { Density } \\
{\left[\mathrm{g} / \mathrm{cm}^{3}\right]} \\
\end{array}$ & $\begin{array}{c}\text { Resistivity } \\
{[\Omega . \mathrm{m}]}\end{array}$ & $\begin{array}{c}\mathrm{d}_{\mathrm{av}} \\
{[\mu \mathrm{m}]}\end{array}$ & $\begin{array}{c}\mathrm{d}_{50} \\
{[\mu \mathrm{m}]} \\
\end{array}$ & $\begin{array}{c}\mathrm{d}_{90} \\
{[\mu \mathrm{m}]} \\
\end{array}$ & $\begin{array}{c}\mathrm{R}_{\mathrm{a}} \\
{[\mu \mathrm{m}]} \\
\end{array}$ & $\begin{array}{c}\mathrm{R}_{\mathrm{t}} \\
{[\mu \mathrm{m}]}\end{array}$ \\
\hline WC & 328 & $1691 \pm 8$ & $8.5 \pm 0.4$ & 9.80 & $4.3 \cdot 10^{-6}$ & 0.254 & 0.115 & 0.54 & 0.87 & 7.39 \\
\hline $\mathrm{TiCN}$ & 284 & $1422 \pm 10$ & $7.0 \pm 0.2$ & 5.76 & $17.0 \cdot 10^{-6}$ & 0.369 & 0.225 & 0.83 & 0.70 & 6.37 \\
\hline TiN & 274 & $1370 \pm 7$ & $5.6 \pm 0.1$ & 5.81 & $4.6 \cdot 10^{-6}$ & 0.384 & 0.245 & 0.86 & 0.65 & 5.16 \\
\hline
\end{tabular}

The investigated composites cover a wide range of material properties. The $\mathrm{ZrO}_{2}-\mathrm{WC}$ composite combines high toughness with high hardness. The $\mathrm{ZrO}_{2}-\mathrm{TiCN}$ composite has a lower toughness as well as lower hardness and the $\mathrm{ZrO}_{2}$-TiN has the lowest toughness and hardness of the investigated ceramics. The grain size distribution of the TiN and TiCN phase is comparable, but significantly coarser than that of the WC phase which was obtained from nanocrystalline WC starting powder.

The $\mathrm{ZrO}_{2}$-based ceramics were manufactured by wire-EDM on a ROBOFIL 2000 (Charmilles Technologies, Switzerland) in demineralised water (dielectric conductivity $5 \mu \mathrm{S} / \mathrm{cm}$ ), using a brass wire (CuZn37) electrode with a diameter of $0.25 \mathrm{~mm}$ and a tensile strength of $500 \mathrm{MPa}$. Initial rough cutting was performed to get a higher MRR. In order to improve the surface quality, consecutive finishing cuts were applied with lower energy input and a shorter duration of the applied energy pulses. In this paper, the wear performance of $\mathrm{ZrO}_{2}$-based composites with the finest EDM regime is investigated. The corresponding roughness parameters $R_{a}$ and $R_{t}$ are listed in Table 1.

Wear testing. The wear behavior of wire-EDM'ed $\mathrm{ZrO}_{2}$-based composites was evaluated using a high frequency tribometer, in which a WC-Co cemented carbide pin was reciprocally slid against a ceramic composite counter plate, in an air-conditioned atmosphere of $23{ }^{\circ} \mathrm{C}$ and a relative humidity of $60 \%$, in accordance with ASTM G133. The pin material (CERATIZIT grade MG12 cemented carbide with 6 wt. \% Co) has a compressive strength of $7.2 \mathrm{GPa}$, a Vickers hardness HV10 of 1913 $\mathrm{kg} / \mathrm{mm}^{2}$, a fracture toughness of $9.3 \mathrm{MPa} \mathrm{m}^{1 / 2}$ and a stiffness of $609 \mathrm{GPa}$. The sliding tip of the pins was a hemisphere with a rounding radius and roughness parameters $R_{a}$ and $R_{t}$ that were measured to be $4.08 \mathrm{~mm}, 0.35 \mu \mathrm{m}$ and $2.68 \mu \mathrm{m}$ respectively.

The contact load was varied from $15 \mathrm{~N}$ up to $35 \mathrm{~N}$, with a stroke length of $15 \mathrm{~mm}$. A sliding velocity of $0.3 \mathrm{~m} / \mathrm{s}$ was applied. The test duration was associated with a sliding distance of $10 \mathrm{~km}$. Before each test, the specimens were cleaned with acetone. After each test, the wear topography was quantified using surface scanning equipment (Somicronic ${ }^{\circledR}$ EMS Surfascan 3D, type SM3, needle type ST305). The wear scars were examined by scanning electron microscopy (SEM, XL-30 FEG, FEI, The Netherlands), equipped with an energy dispersion X-ray spectroscopy system (EDS).

\section{Results and discussion}

Friction and wear depth. Typical and representative wear data, obtained during real-time monitoring of friction and combined wear depth for finish cut wire-EDM $\mathrm{ZrO}_{2}$-based composite flat/ WC-Co pin combination as function of the sliding distance are shown in Fig. 1. Each curve is an average of at least two wear experiments performed under identical conditions, with a standard deviation of less than $10 \%$ between different samples of the same material. The error bars indicating the extent of the variations are excluded to make the figure better readable.

The friction coefficient and wear loss are noticed to increase abruptly during the first metres of sliding and then gradually ascend further due to growing pin on plate contact surface. After a running-in stage, the tribosystem reaches a steady state with almost linearly increasing wear depth as function of sliding distance and, at the same time, the friction coefficient drops down and subsequently rises towards its prior level. The fluctuations in the friction curves, both in the initial and steady state regime, are due to a continuous breaking and regeneration of micro junctions and 
indicate a more pronounced adhesion of both contact surfaces. The dynamic and static component of friction are found to vary very similarly as function of the sliding distance, however at a different level. The instabilities in the friction curves during the first sliding kilometers can be related to the changes in the sliding contact surface due to the removal of the wire-EDM induced recast layer.

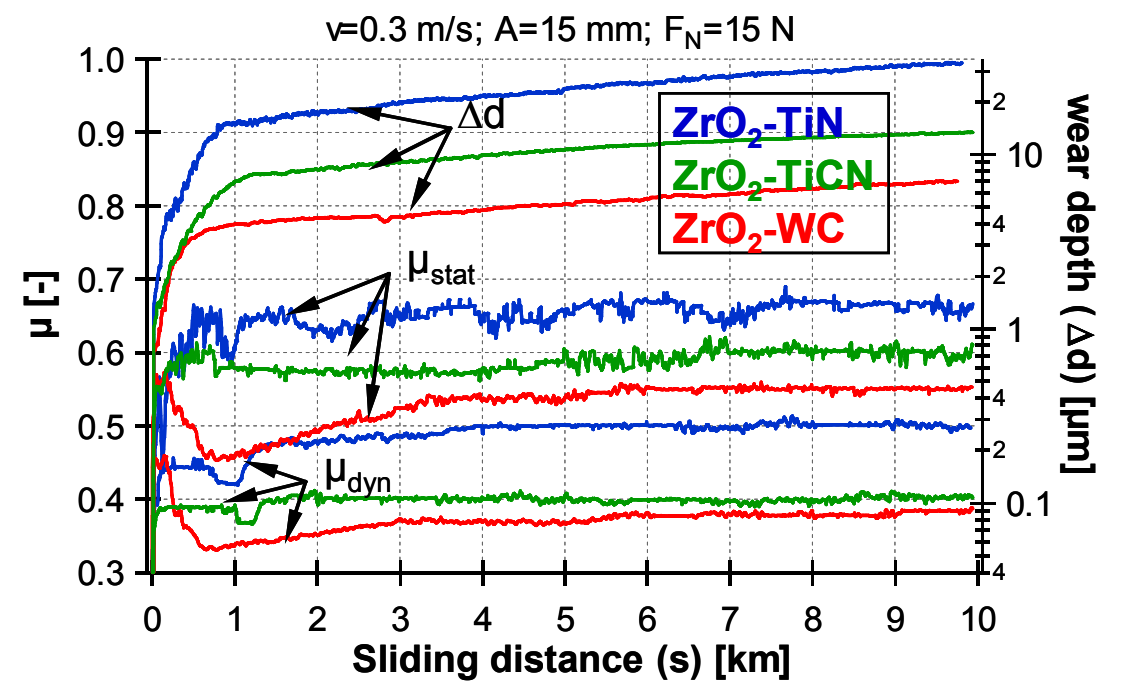

Fig. 1: real-time wear depth and static and dynamic friction coefficient for wire-EDM'ed $\mathrm{ZrO}_{2}$-based composite flat/ WC-Co pin pairs sliding at $0.3 \mathrm{~m} / \mathrm{s}$, under a $15 \mathrm{~N}$ contact load

Post-mortem wear characterisation. In order to examine the reciprocating sliding wear behavior, research was mainly focused on the steady state regime. From the obtained 3D wear track topographies for the ceramic composites, the corresponding wear scar volumes and volumetric wear rates, i.e., the ratio of the wear loss and the product of the applied load and sliding distance, were derived, Table 2. Under identical conditions of wear path, sliding speed and contact load, the smallest depth and width of the wear scars are measured for the $\mathrm{ZrO}_{2}-\mathrm{WC}$ composite, whereas the highest values occur for $\mathrm{ZrO}_{2}$-TiN specimens, in full agreement with the results of Fig 1 . Comparing these results with the online measured wear depth reveals small deviations. This is partly attributed to the wear of the pin, that is not taken into account during post-mortem quantification.

Table 2: wear scar dimensions for $\mathrm{ZrO}_{2}$-based composites slid against $\mathrm{WC}$-Co $\left(\mathrm{s}=10 \mathrm{~km}, \mathrm{~F}_{\mathrm{N}}=15 \mathrm{~N}\right)$

\begin{tabular}{ccccc}
\hline Grade & Width $[\mathrm{mm}]$ & Depth $[\mu \mathrm{m}]$ & Volume $\left[10^{-3} \mathrm{~mm}^{3}\right]$ & $\mathrm{k}_{\mathrm{V}}(10 \mathrm{~km})\left[10^{-6} \mathrm{~mm}^{3} \cdot \mathrm{N}^{-1} \cdot \mathrm{m}^{-1}\right]$ \\
\hline $\mathrm{ZrO}_{2}$-WC & 1.05 & 4.8 & 7.9 & 0.053 \\
$\mathrm{ZrO}_{2}-\mathrm{TiCN}$ & 1.15 & 12.8 & 92.3 & 0.61 \\
$\mathrm{ZrO}_{2}$-TiN & 1.55 & 23.6 & 320 & 2.13 \\
\hline
\end{tabular}

Wear surface analysis. The different wear levels, wear characteristics and worn surface morphologies are mainly caused by plastic deformation controlled and microcrack controlled wear mechanisms [8]. SEM surface views of the wear tracks on the $\mathrm{ZrO}_{2}$-based composites studied, after sliding $10 \mathrm{~km}$ against WC-Co pins at $0.3 \mathrm{~m} / \mathrm{s}$ velocity under various contact loads, revealed the presence of wear debris and abrasive grooves, Fig. 2. With $\mathrm{ZrO}_{2}-\mathrm{TiN}$ and $\mathrm{ZrO}_{2}-\mathrm{WC}$ composites, the wear track is covered by a continuous layer of wear debris with microcracks perpendicular to the sliding direction and delaminated areas, Fig. 2(a). The $\mathrm{ZrO}_{2}-\mathrm{TiCN}$ composite wear surface microstructure on the other hand, mainly corresponds to the base material, i.e. the original microstructure is still visible and no microcracks are detected. In some regions however, the formation of the wear debris layer is initiated, Fig. 2(b). Furthermore, the formation of a continuous debris layer in the wear track is only observed with a contact load of $35 \mathrm{~N}$. When testing at 15 or 25 $\mathrm{N}$, the wear track looks mainly like the polished substrate material. 
(a)

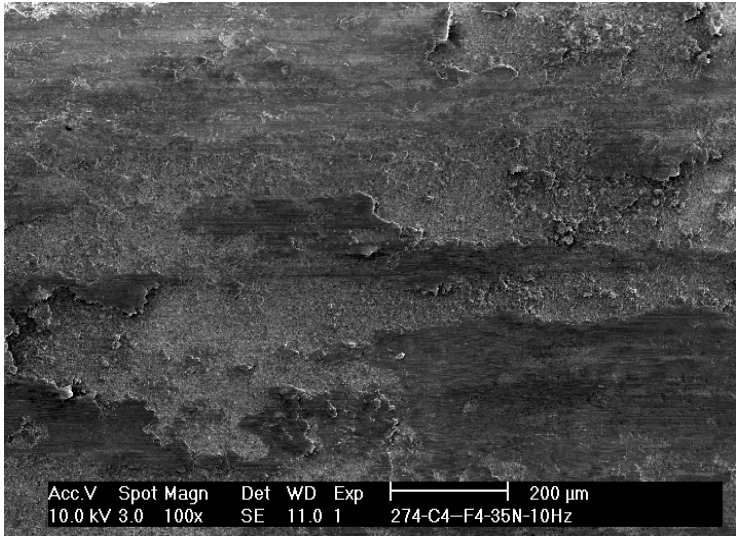

(b)

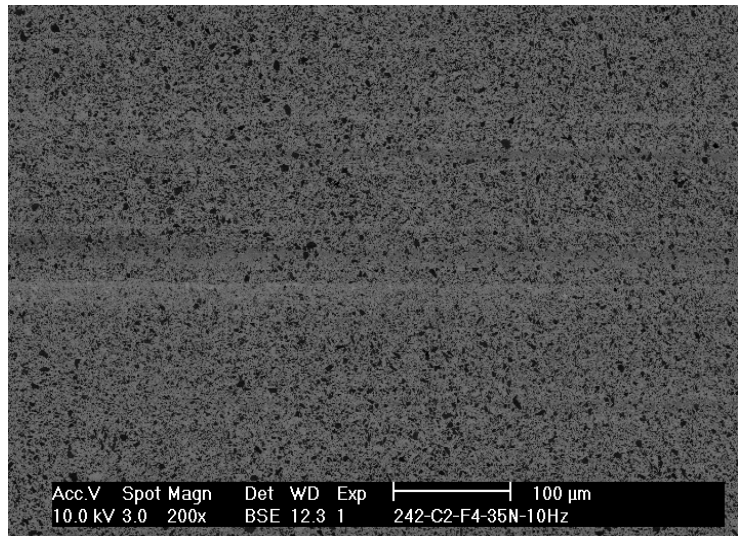

Fig. 2: SEM surface views in the wear track of wire-EDM'ed (a) $\mathrm{ZrO}_{2}$-TiN and (b) $\mathrm{ZrO}_{2}$-TiCN based composites after sliding $10 \mathrm{~km}$ at $0.3 \mathrm{~m} / \mathrm{s}$ under a $35 \mathrm{~N}$ contact load

\section{Conclusions}

Dry reciprocative sliding experiments of wire-EDM'ed $\mathrm{ZrO}_{2}-\mathrm{WC}, \mathrm{ZrO}_{2}-\mathrm{TiCN}$ and $\mathrm{ZrO}_{2}-\mathrm{TiN}$ composites against WC-Co pins, revealed a significant influence of the secondary phase material on their friction and wear characteristics. The overall specific wear rates after a wear path length of 10 $\mathrm{km}$ varied between $5 \cdot 10^{-8}$ and $2.1 \cdot 10^{-6} \mathrm{~mm}^{3} \cdot \mathrm{N}^{-1} \cdot \mathrm{m}^{-1}$. The most favorable tribological properties were encountered with the $\mathrm{ZrO}_{2}-\mathrm{WC}$ composites, whereas the $\mathrm{ZrO}_{2}-\mathrm{TiN}$ materials exhibited the lowest wear resistance. The wear resistance of the $\mathrm{ZrO}_{2}-\mathrm{TiCN}$ composite was in-between that of the $\mathrm{ZrO}_{2}-$ $\mathrm{WC}$ and -TiN composites, in agreement with the relative hardness and fracture toughness of the investigated composites. The $\mathrm{ZrO}_{2}-\mathrm{TiCN}$ composite appears to be less prone to the formation of a continuous debris layer compared to the $\mathrm{ZrO}_{2}-\mathrm{WC}$ and $\mathrm{ZrO}_{2}-\mathrm{TiN}$ composites.

\section{Acknowledgements}

This research was co-financed by the Flemish Institute for the promotion of Innovation by Science and Technology in industry (IWT). The authors gratefully recognize the support and scientific contributions from the Ghent University (UGent) and the Catholic Leuven University (K.U.Leuven). Special appreciation goes to CERATIZIT for supplying the cemented carbide pins.

\section{References}

[1] S.W. Lee, S.M. Hsu, M.C. Shen, Ceramic wear maps: zirconia, J. Am. Ceram. Soc., 76 (1993), 1937-1947

[2] D.F. Wang, J. Li and Z.Y. Man, Study of abrasive wear resistance of transformation toughened ceramics, Wear 165 (1993), 159-167

[3] J. Kozak, K.P. Rajurkar, N. Chandarana, Machining of low electrical conductive materials by wire electrical discharge machining (WEDM), J. Mat. Proc. Tech., Vol. 146/1-3 (2004), 266-271

[4] B. Lauwers, J.-P. Kruth, W. Liu, W. Eeraerts, B. Schacht and P. Bleys, Investigation of material removal mechanisms in EDM of composite ceramic materials, J. Mat. Proc. Tech. 146/1-3 (2004), 347-352

[5] S. Salehi, O. Van der Biest and J. Vleugels, Electrically conductive $\mathrm{ZrO}_{2}$-TiN composites, J. Europ. Ceram. Soc., 26 (2006), 3173-3179

[6] G. Anné, S. Put, K. Vanmeensel, D. Jiang, J. Vleugels, O. Van der Biest, Hard, tough and strong $\mathrm{ZrO}_{2}-\mathrm{WC}$ composites from nanosized powders. J. Europ. Ceram. Soc., 25 (2005), 55-63

[7] J. Vleugels and $\mathrm{O}$. Van der Biest, Development and characterization of $\mathrm{Y}_{2} \mathrm{O}_{3}$-stabilized $\mathrm{ZrO}_{2}(\mathrm{Y}$-TZP) composites with $\mathrm{TiB}_{2}$, TiN, TiC, and $\mathrm{TiC}_{0.5} \mathrm{~N}_{0.5}$, J. Am. Ceram. Soc. 82 (1999), 2717-2720

[8] A.G. Evans, D.B. Marshall, Wear mechanisms in ceramics, Fundam. Friction Wear Mater. ASM (1980), 439-452 